\title{
VIVENCIANDO A HIPERTENSÃO ARTERIAL: CONSTRUÇÃO DE SIGNIFICADOS E SUAS IMPLICAÇÕES PARA A VIDA COTIDIANA ${ }^{1}$
}

\author{
EXPERIENCING HYPERTENSION: THE CONSTRUCTION OF MEANINGS \\ AND ITS IMPLICATIONS TO THE DAILY LIFE \\ VIVIENDO LA HIPERTENSIÓN ARTERIAL: LA CONSTRUCCIÓN DE \\ SIGNIFICADOS Y SUS IMPLICACIONES EN LO COTIDIANO
}

\author{
Maria Rosimar de Jesus Barbosa ${ }^{2}$ \\ Maria Salete Bessa Jorge ${ }^{3}$
}

RESUMO: O estudo é um recorte de uma dissertação de mestrado. Trata-se das Representaçöes Sociais da hipertensão arterial e de suas causas, assim como tenta compreender as imagens e protótipos que a mulher portadora de hipertensão tem sobre sua situação, como elas se percebem na familia e em interação com os outros. O número de atrizes sociais envolvidas na investigação foi de vinte e uma mulheres participantes de um programa de controle de hipertensão localizado na periferia de Fortaleza- Ceará. Os resultados mostram que viver com hipertensāo é para essas mulheres experienciar o quanto é dificil e como são muitas as limitaçōes da vida social e familiar. A imagem que elas fazem de si mesmas é de pessoas "diferentes", que vivem sob constante ameaça de morte ou de invalidez, levando-as a um sofrimento psiquico. As várias restriçōes impostas pela doença colocam-nas praticamente à margem da vida social normal.

PALAVRAS-CHAVE: mulheres, hipertensão arterial, Representaçōes Sociais

\section{INTRODUÇÃO}

Hoje a hipertensão arterial se revela como um dos principais e talvez um dos mais agravantes riscos para as doenças cardiovasculares no mundo inteiro. Acredito que tal agravo está relacionado às consequeências da urbanização e da industrialização avassaladora, modificando comportamentos e estilo de vida, favorecendo assim o desenvolvimento e agravamento das doenças chamadas "do coração".

Os números são alarmantes, de acordo com III CONSENSO BRASILEIRO DE HIPERTENSÄO ARTERIAL (1998). Estima-se que aproximadamente $15 \%$ a $20 \%$ da população brasileira sofrem de hipertensão arterial, sendo, portanto, um grande e grave problema de saúde pública no País, correspondendo ainda a $40 \%$ das causas de absenteismo e aposentadorias precoces por invalidez.

O conhecimento da prevalência da hipertensão arterial e de seus fatores de risco possui grande valor na orientação do planejamento das politicas de saúde voltadas para prevenção e detecção precoce das doenças crônicas no Pais (Piccini ; Victora,1994).

Segundo Amodeu (1995), a hipertensão arterial é uma doença considerada de caráter multigênico e multifatorial , que quando não tratada adequadamente acarreta danos ao organismo, principalmente em órgãos como o coração, rins e cérebro,

Cada vez mais jovens vêm sendo acometidos pela hipertensăo arterial, constituindo-se em um dos quadros mórbidos da chamada sociedade moderna. Nesse contexto, a mulher se

'Este trabalho é parte de Dissertação de Mestrado Acadêmico em Saúde Pública.

${ }^{2}$ Enfermeira, Especialista e Mestranda em Saúde Pública pela UECE.

${ }^{3}$ Enfermeira, Doutora em Enfermagem e Orientadora da Dissertação. Docente do Curso de Mestrado Acadêmico em Saúde Pública. Universidade Estadual do Ceará. 
encontra posta, mesmo as que não estão no mercado de trabalho formal, engrossando os números de prevalência da doença, responsáveis por grande quantidade de mortes prematuras entre adultos (Martins et al.,1993).

O diagnóstico da hipertensão arterial é basicamente estabelecido pela confirmação de niveis tensionais permanentemente elevados acima dos limites de normalidade, desde que essa aferição seja realizada com métodos e condições apropriadas. Portanto, o elementochave para o estabelecimento do diagnóstico da hipertensão arterial é a medida da pressão arterial.

Esse estabelecimento do diagnóstico, muitas vezes, é tardio, visto que não existe o hábito de verificação dos niveis pressóricos por parte dos clientes. A procura dos serviços de saúde pela população está relacionada à presença de sintomas, ficando, portanto, na maioria das vezes, um diagnóstico tardio associado freqüentemente com lesões em órgãos-alvo, pois o mais comum na hipertensão arterial é a assintomatologia (Amodeu,1995).

Muitos especialistas, na área de saúde, denominam hipertensão arterial como sendo a doença que mata "silenciosamente", já que é descoberta quase sempre ao acaso e a adesão ao tratamento é muito dificil, pois seus fundamentos são as modificações do estilo de vida do individuo.

Nessa perspectiva, como cuidadora dessas mulheres com hipertensão que sou, na intervenção e no tratamento, busquei estudar as Representações Sociais (R.S.), na tentativa de revelar: as representações dessas mulheres, os seus comportamentos, vivências, experiências, atitudes e imagens; com base nos resultados encontrados poder intervir mais eficazmente no tratamento e prevenção de complicações advindas da doença.

Assim, nesta pesquisa, busquei identificar as Representações Sociais da hipertensão e suas causas, bem como compreender as imagens e protótipos da mulher portadora de hipertensão sobre sua situação, observando como elas se percebem na familia e em interação com os outros, identificando as barreiras frente ao tratamento a partir das RS.

\section{TEORIA DAS REPRESENTAÇÕES SOCIAIS COMO SUPORTE TEÓRICO METODOLÓGICO}

A R.S. pode ser compreendida como uma representação mental apreendida na consciência, advinda de figuras, imagens, atos ou de experiências, às quais os individuos possam atribuir significados e simbolos, de acordo com sua percepção sobre estes, originando, assim, comportamentos ou atitudes (Rodrigues ,1999).

Para Figueiredo (1999), as R.S. possuem potencial de poder explicitar o mundo simbólico, denotando os referenciais de ação e comunicação, sem, contudo, desconfigurar uma percepção mais dialética, buscando assim dar conta da maioria dos fatores intrinsecos na realidade da vida. É através das R.S. que se pode ter acesso ao mundo intimo de grupos sociais, englobando suas condições de vida, opiniões, práticas conscientes ou não, daquilo que acreditam ser suas "verdades" e/ou suas " ciências".

Minayo (1996), define o termo Representações Sociais como categoria de pensamento, de ação e de sentimentos que expressam a realidade, tentando dessa forma explicá-la, justificála ou questioná-la. Portanto os atores sociais possuem como senso comum: idéias, imagens, concepções e visão de mundo sobre a realidade em que vivem.

Segundo Spink (1995), as R.S. enfocadas como produto emergem como pensamento constituido ou campo estruturado. Nessa perspectiva, o estudo utilizando tais representaçöes visa a desprender seus elementos constitutivos como as informaçōes, opiniōes, imagens e crenças.

Nesse sentido, devo estar capacitada para compreender que a expressão de realidade criada por uma Representação é algo frágil, que pode ser facilmente quebrado por minúsculos contratempos. Entender a Teoria das Representações Sociais traz-me subsidios para clareamento das representações que se mostram dentro das interações sociais, que na minha 
realidade de estudo diz respeito às mulheres hipertensas.

Portanto, diante da construção do objeto de pesquisa, tendo como base a Teoria das Representaçōes Sociais, acreditamos ser possivel chegar à compreensão da mulher portadora de hipertensão, situada no seu âmbito familiar. A partir dai transformar as representaçōes de sua imagem como mulher, mãe, dona-de-casa e hipertensa.

\section{TRAJETÓRIA METODOLÓGICA}

Esta pesquisa empregou uma abordagem qualitativa de caráter exploratório, cujo desenvolvimento se orientou pela Teoria das Representaçōes Sociais, com base em Moscovici (1978).

A opção pela pesquisa qualitativa deveu-se a uma postura científica voltada para compreensāo de processos subjetivos, sejam grupais e/ou sociais, que visa o estudo de individuos e dos grupos através de seus discursos, costumes, tradiçōes, buscando entendê-los dando significados à lógica interna dos discursos, assim como à retórica, aos lapsos e às contradições que ocorreram tentando encontrar o processo de construção da representação da doença.

O local de eleição da pesquisa para realização do trabalho é a cidade de Fortaleza, no Estado do Ceará-Brasil. O presente estudo foi desenvolvido junto às mulheres com hipertensão pertencentes a um programa de controle de hipertensão, localizado num bairro da periferia , inserido numa instituição hospitalar de atenção secundária da rede pública municipal.

A amostra foi constituida por meio de uma seleçăo intencional, entre os clientes cadastrados no serviço de ambulatório local citado. Esta escolha teve como requisitos básicos: ser mulher; estar sendo acompanhada pelo programa há pelo menos um ano e ser portadora de hipertensão.

Foram escolhidas inicialmente, onze mulheres, divididas em dois grupos, um constituido de cinco participantes e o outro de seis. Realizamos dois grupos focais com cada um desses grupos, perfazendo um total de quatro grupos focais.

Diante dos discursos coletados nos grupos focais, realizamos entrevistas de aprofundamento abordando os achados com outras dez mulheres portadoras de hipertensão arterial e pertencentes ao programa de controle de hipertensão analisado, levando em consideração os requisitos básicos estabelecidos no estudo para fazer parte da amostra.

Dai obtivemos um total de vinte e uma atrizes sociais participantes da investigação, número este determinado e pautado na saturação teórica revelada nos discursos.

A pesquisa foi realizada somente com as mulheres que aceitaram participar do estudo, sendo esclarecido os objetivos da investigaçăo e resguardado o anonimato dessas pessoas.

O periodo de coleta das discussōes foi mantido até o momento em que se iniciou a repetição e, a partir dai, as discussões foram encaminhadas para regularização de convergências, mostrando que as Representações Sociais investigadas estavam se delineando. O periodo de coleta das descrições abrangeu de abril a agosto de 2000.

A análise dos dados coletados proposta para este estudo foi a análise de conteúdo ( $A C)$, tendo como base o referencial de Bardin (1977).

Quando ocorrer a aplicação da análise de conteúdo, a opção pela técnica que se revelou como a mais apropriada para essa investigação, recaiu no estabelecimento como unidade de análise, a enunciação. Nessa perspectiva, esse meio facilitou a descoberta do que se encontrou na essência dos discursos surgidos nos grupos focais e em entrevistas realizadas.

\section{DESCREVENDO OS RESULTADOS}

Os dados analisados sugerem que a construçăo de significados para a doença emergem a partir de vários temas : a experiência subjetiva da doença, as explicaçōes quanto à origem da 
doença, a situação do seu convivio familiar, a interação social enquanto portadora de hipertensão e as barreiras vivenciadas frente ao tratamento da doença por cada uma das entrevistadas.

A hipertensão arterial discursada nas falas das atrizes sociais envolvidas na investigação, revelam momentos de tensão constantes relacionados aos medos entrelaçados e firmados nas discussões entre os grupos focais e entrevistas trabalhadas. Elas a representam como medo da morte antecipada, prenunciada pelas mulheres portadoras de tal patologia. Tal Representação Social ficou ancorada nos medos presentes: o medo da própria morte, da dependência de cuidados dos outros, do possivel problema do coraçăo, da falta de ar que possa ocorrer, além do derrame cerebral e infarto que possam vir a acometê-las.

Nesse contexto, fica claro nos discursos que tais elementos que vão traduzindo o significado da pressão alta ficam reafirmados com as seguintes falas:

... o medo de ficar doente em cima de uma cama, medo de ficar paralitica dependendo dos outros...

... tenho medo de morrer, de ter um derrame cerebral.

O medo da invalidez, associado ao medo de morrer é outro aspecto enfocado como consequéencia da doença envolvendo assim o medo da dependência do outro, diante da possibilidade de ficar paralitica após um acidente vascular cerebral.

Sendo as representações elementos de pensamento que podem tornar-se realidade (Vachod; Santos, 1996), "o medo da invalidez" é grande, pois as atrizes sociais estudadas vêem no pensar, enquanto hipertensas, a possibilidade de mudanças irreversiveis no corpo advindas do processo de adoecer com hipertensão frente às complicações tão bem vivenciadas nos significados ditos pelas mulheres, como trombose ou derrame cerebral explicito nos discursos.

A vontade de nāo ficar inválidas pode gerar sofrimento e, enquanto sofrimento provocado pela doença, este pode representar a experiência que desintegra a unidade da pessoa e, ao mesmo tempo, pode servir como matriz para a construção da identidade social dos sujeitos (Duarte; Leal, 1998).

O medo é uma das premissas que mais rodeiam as idéias dos discursos e que se torna marcante pela repetição da palavra nas falas, assim como uma afirmação e reafirmação de pensamentos, ou ainda ambivalências destes. Nesse sentido, o medo torna-se recorrente na Representação Social da pressão alta e mostra-se relacionada à preocupação com o futuro, pela separação que poderá causar, principalmente dos filhos, bem como pela possibilidade de morte súbita que a doença possa ocasionar e ainda incertezas quanto aos problemas financeiros que já vivenciados poderăo agravar-se como desenrolar dos tempos. Tudo isso fica objetivado nos discursos presentes nas falas de tais mulheres, como explicitam em algumas delas:

É porque agora quando eu tenho muita raiva eu começo a sangrar pelo nariz e pela boca (...) dai então eu fico com muito medo de morrer, eu tenho medo de morrer! (...) A única coisa que eu tenho medo é de morrer e deixar meus filhos...

A primeira coisa que vem na minha cabeça é de que eu posso morrer de uma hora pra outra, né?, porque a pressăo alta ela mata e muito rápido...

Percebo assim que essas mulheres vêem a pressão alta como uma doença que pode levá-las à morte, ancorando este medo na origem de doença, experiência esta vivenciada pelo exemplo de seus familiares, deixando claro em seus discursos suas incertezas sobre o futuro da doença.

Eu penso assim que vou ficar doente... penso um monte de coisa ruim, sei lá...eu só 
Vivenciando a hipertensäo arterial...

penso em ficar doente e penso que vou morrer como a minha irmã morreu. Ela sentiu um nervoso ai (...) e minha sobrinha levou ela para o hospital e de lá não voltou mais, já voltou morta, tudo de uma raiva que ela teve. É disso que eu tenho medo...

Essa condição de "morte anunciada" está intrinseca ao processo de adoecer que o individuo imbute quando na situação da doença envolvendo tanto fenômenos clínicos como sociológicos que contribuem para o sofrimento do ser.

Nesse sentido, as Representações Sociais da doença também remetem às raizes tradicionais na percepção de mundo individual, com suas crenças e valores, todas elas relativas à morte, vida, ao corpo e as suas experiências de vida (Alves; Minayo, 1994).

Portanto, na tentativa de compreender o porquê da percepção dessas mulheres enquanto portadoras de hipertensão de "morte antecipada", é necessário visualizar que pensar em doença e suas causas é preciso pensar a cultura e sociedade em que esse grupo se encontra inserido, entendendo a compreensão da doença como experiência, onde analisar seu significado para o próprio doente e para os que o cercam, busca-se implicações clínicas da relação entre a doença e a cura entre a sociedade e a cultura (Silveira, 2000).

O fato de poder continuar suas tarefas rotineiras como o trabalho doméstico, cuidados com filhos e familiares, levam essas mulheres a não se considerarem indivíduos portadores de uma doença, pois doença no sentido vivido por este grupo é a incapacidade de executar tais atividades, onde a presença da hipertensão arterial como doença é negada em seus discursos.

Eu não me acho uma mulher doente de jeito nenhum (...) eu me acho uma mulher saudável, bonita e maravilhosa, então não sou doente...

Apesar de serem conscientes da cronicidade da patologia, observo nos discursos a esperança de cura dessas mulheres.

(...) quero continuar até melhorar ou quem sabe até ficar boa, sei lá, até que Deus quiser ... o cuidado é a vida eterna, já que não tem cura!

(...) me trato pra mim ficar boa de vez, porque do contrário se você não continuar o tratamento não tem recuperação, tem só uma melhora, então a gente conseguir se recuperar, seria ótimo (...) voltar ao normal .

Algumas das atrizes sociais diante do sofrimento de serem doentes de hipertensão, anunciando uma morte ainda inexistente, pois não são pessoas consideradas em fase terminal no leito de morte, e sabidamente cientes do estado de cronicidade da doença, vivem a possibilidade da cura representando a compensação pelo sofrimento de estar doente, funcionando como elemento sistematizador da experiência e trajetória, bem como constituindo o parâmetro que demarca o reconhecimento social legitimador do sofrimento.

Na opinião de Duarte e Leal (1998) é a condição de ser/estar curado, estado este reconhecido e avaliado pelo grupo, que pode conferir credibilidade ao estado de sofrimento. Nessa perspectiva, o autor coloca que o estado de sofrimento se constrói a partir de sua própria negação, primeiramente através da cura e segundo pela possibilidade de tentar esquecer, omitir e até mesmo abstrair a experiência de ser doente.

Assim, a doença revelada como morte anunciada, diante de todas as outras Representações Sociais encontradas para estas mulheres que se percebem tendo de mudar seus hábitos alimentares e atitudes de toda a vida, incidem em angústia e sofrimento psíquico devido a estas mudanças, interferindo significamente em sua relação cotidiana com o mundo em que vivem e consigo mesmas.

As entrevistadas levantam várias causas para a doença que não são excludentes e 
podem ser complementares como a vida muito agitada, preocupaçöes, problemas sejam eles financeiros ou conjugais, idade avançada, hereditariedade, hábitos alimentares e fatores emocionais. A ênfase maior é dada a problemas e a preocupações como as principais causas da hipertensão, refletindo num estilo de vida conturbado. Repetem isto em vários momentos de seus discursos. Estas explicaçōes etiológicas foram mais explicitadas pelo fato de vivenciarem constantes conflitos intrafamiliares que desencandeiam preocupações para as mesmas, levandoas a crises hipertensivas e a queixas de sintomatologia típica e freqüente como cefaléia, dor precordial e dispnéia, justificada pelas crises nervosas. Conforme o relato:

... com qualquer problema a gente fica com pressão alta (...) Eu acho que as principais que causaram minha pressão alta foi minha vida muito agitada.... meus problemas....

A explicação da vida muito agitada se dá pela atenção reforçada à familia, procurando ser a supermãe, dona-de-casa, procurando atender a todas as atividades domésticas e as suas tarefas de mãe incubida. Essa "agitação" transforma seu dia-a-dia em algo repetitivo, monótono e estressante, fatos estes entendidos como causadores de muitas das crises hipertensivas.

As preocupações mais representadas pelo grupo são as referentes às preocupaçōes com o bem-estar dos familiares, buscando administrar os problemas financeiros que afetam todos os componentes da familia, como o desemprego desde esposo até os filhos, muitas vezes, tornando-as definitivamente as chefes de suas familias.

Eu sou o homem e a mulher da casa, então eu tenho que fazer tudo, então eu tenho aquela preocupação de não deixar faltar nada (...)

A explicação de que os fatores emocionais podem originar a doença fica muito firme nos discursos como um todo e está explicita no discurso que nos diz: Eu sou hipertensa por emoção, assim também a hipertensăo pode ter sido causada pelo "nervosismo" como diz o seguinte relato Eu acho que foi o nervo agitado que subiu minha pressão (...), já que se recorda de ter tido sempre problemas emocionais, nomeando a doença de "doença dos nervos".

Nesta concepção, está presente a idéia de unicidade entre corpo e mente sendo que a mente pode vir a provocar alteraçōes no corpo.

Embora não consideradas satisfatórias as transposições mecânicas das induçöes e deduçōes fisico-biológicas para a discussão da participação dos fatores tidos como psicossociais na produção do adoecer, Pitta (1999) cita que há evidências indicando que qualquer fator psicossocial inespecifico poderá estar associado a uma patologia ou utilidade em se buscar estressores isolados para doenças isoladas, uma vez que, como concordam alguns pesquisadores na área, todas as doenças podem estar relacionadas a tais agentes. Nesse sentido, pode-se explicar a "doença dos nervos" como Representação Social da doença hipertensão arterial.

Alguns eixos relativos ao convivio familiar das mulheres portadoras de hipertensão arterial que nos discursos, muitas vezes ambivalentes e contraditórios, relataram uma visão da realidade do cotidiano familiar dessas mulheres, que possuindo uma doença crônica, buscam na unidade familiar o sustentáculo da resistência e aceitação da patologia.

Entretanto, sendo a familia considerada para alguns como o bem maior obtido, algumas dessas mulheres revelaram uma convivência desarmoniosa voltada para freqüente tensão articulada e/ou associada às preocupaçōes do dia-a-dia, refletindo na insatisfação e insucesso da sua recuperação e tratamento da doença como um todo.

Todas as envolvidas no estudo apontaram "preocupações" como elemento presente na familia, atribuida a responsabilidade maior e em geral ao papel de mães e filhas que todas exercem. As preocupaçōes mais relatadas são as relativas aos cuidados com os filhos e pais, 
bem como à saúde dos familiares como um todo. O papel cuidador dos entes familiares doentios ficam sob sua atribuição.

A minha familia...é uma coisa horrivel...mamãe doente, ali tem que todo dia dar aqueles remédios, dar insulina, dar os comprimidos. É todo dia é aquela mesma coisa, a gente não pode nem dormir ou cochilar, não pode esquecer...

No seio familiar, segundo Silva e Franco (1996), é a mulher, principalmente dona-decasa, quem tem grande participação e responsabilidade na questão de saúde e doença. Ela é quem avalia as condições de saúde, assim como toma as iniciativas de procurar os recursos de que a comunidade dispõe, buscando soluçōes para a problemática familiar.

As mulheres com hipertensão desempenham, portanto, o papel de "cuidadoras" em suas familias e tudo isso gera dificuldade no enfrentamento de seus problemas pessoais, onde não conseguem, muitas vezes, exteriorizar seus sentimentos, não permitindo autenticidade em seus comportamentos, tendo em vista seu condicionamento social e as transformações oriundas das relaçōes familiares. Esses fatos assemelham-se ao estudo de Cereser (1996) trabalhando a vivência familiar de mulheres no sul do pais.

Diante da questão representada aqui, como convivio familiar, percebo que as representaçōes sociais resultantes dos discursos interagidos dos grupos focais e entrevistas levam a um sofrimento psiquico forte e importante na vida dessas mulheres, que diante de uma situação de doença crônica, dançam, inventam, transformam coisas aparentemente impossiveis em algo real e relevante. Tais situaçőes trazem tristeza e sofrimento muitas vezes, já que familia no seu contexto maior deveria trazer motivação e não insatisfação e sobrecarga de papéis vivenciados por estes seres que de frágeis nem o nome possuem.

Nesse sentido, buscando tais representaçōes nos discursos das mulheres com hipertensão nos grupos focais e em entrevistas realizadas quanto ao convivio social, a desvalorização por serem doentes de tal patologia, revelada pelos comentários desagradáveis a respeito da doença no convívio social, foi encontrada como fator negativo e desencadeador de crises hipertensivas. Tal argumento mostra-se explicito na seguinte fala:

(...) no meu caso, o convivio social já me afeta, porque a gente vai a uma festinha, já começa os comentários, já tá todo mundo bem informado: Valha, tu já é doente, tão nova ( fala dos outros numa festa com amigos). Todo mundo te olha com medo, a gente fica assim, já olha com olhar assim... parece que é de cristal, vai se quebrar já...

Nessa fala os comentários desagradáveis na convivência em sociedade aparece como algo dificil de suportar e algo que está presente tanto na relação do individuo com ele mesmo, pois diz respeito ao seu corpo como também nas relações interpessoais, resultando, conseqüentemente, em sofrimento psíquico e recusa da vida em sociedade, muitas vezes buscando o isolamento como fuga pessoal.

Quanto às barreiras frente ao tratamento da doença, as atrizes sociais mostram-se informadas quanto às restriçőes alimentares impostas e no convivio em sociedade revelaram comportarem-se como "doentes" que necessitam do cuidado e atenção com os excessos, mesmo que năo aceitando bem tal imposição.

Se eu vou a um aniversário eu me comporto assim normal e eu como de tudo um pouquinho, eu só não faço é exceder, né?

Alves (1998), ao investigar sobre as Representações Sociais da hipertensão numa comunidade carioca, refere que esse grupo também percebe as restrições alimentares ou a 
mudança no estilo de vida desses individuos como uma barreira que limita os pequenos prazeres da vida. Retrata tal achado com a frase: "(. . . ) não é só a comida que perde o sal. É a vida também que torna-se insossa. Esse é apenas um dos prazeres suspensos(. . .)"(p.163).

A doença nesse sentido traz esse comportamento como preocupação que algumas dessas mulheres, já sensiveis à sintomatologia, apresentam sintomas que as deixam ansiosas pela possibilidade de descontrole dos niveis pressóricos, dai a atenção com os erros alimentares.

A experiência com a doença hipertensão arterial é única para cada uma das entrevistadas. A ela são atribuidas barreiras que mobilizam comportamentos, insatisfaçőes e afetos que muitas vezes alteram completamente a vida delas e podem levá-las a resultados năo satisfatórios com relaçăo à doença em si (aceitação), assim como o tratamento com a sua manutenção diária.

\section{CONSIDERAÇÖES FINAIS}

Permitindo o resgate do conhecimento do senso comum aproximando este saber popular com o saber científico, do mundo intelectual tido como saber "quase" absoluto, as representações sociais propõem esse ligamento, ou melhor dizendo, essa transparência de saberes, transformando aquilo que parecia năo ter importância em algo relevante para a compreensão do processo de adoecer com hipertensăo arterial por exemplo.

No decorrer de toda a análise dos discursos, foi possivel perceber o quanto a experiência com a hipertensão arterial é dificil e como são muitas as limitações da vida social e familiar. Ficando explícito nesse desenrolar da doença que viver com tal moléstia é uma arte, exigindo das atrizes sociais em seu palco (a vida) cenas e elementos, diante de sua grande criatividade enquanto mulheres, mães, trabalhadoras, esposas e doentes que são, no enfrentamento de permanecer com a doença pelo resto de suas vidas.

As explicações expressas por nossos sujeitos relativa à representação da doença estăo representadas como "morte anunciada", "medo da invalidez", "doença dos nervos", " conflitos familiares", " interação social diferenciada" e " barreiras " enfrentadas.

Reflexo de todas as Representações Sociais vivenciadas denota-se que quando não tinham a doença, as mulheres se sentiam participantes da vida social de que faziam parte no seu cotidiano.

Nessa perspectiva, parece que a imagem que essas mulheres fazem de si mesmas é de uma pessoa "diferente", que vive sob constante ameaça de morte ou de invalidez. E as várias restrições impostas pela doença as colocam praticamente à margem da vida social normal.

E assim a hipertensão arterial, ainda que passivel de prevenção, detecção precoce e tratamento, continua sendo uma das maiores causas da morbidade e mortalidade de milhões de pessoas em todo o mundo. Nesse contexto, torna-se necessária uma maior prevenção para evitar que o número de hipertensos, de mortes ou de seqüelas cresçam indiscriminadamente, assim como tratar adequadamente os já diagnosticados é relevante. Buscando entendê-los dentro de uma concepção menos biologista, priorizando a interação entre os profissionais de saúde e hipertensos, dentro de um sistema de saúde funcionante, o serviço se torna eficaz para o encontro de um maior número de adesão de individuos ao tratamento imposto, que, como visto na literatura e discursos das mulheres com hipertensăo é algo, além de dificil, sofredor.

ABSTRACT: The present study originated from a master's thesis. It depicts the Social Representations
and causes of hypertension, as well as tries to understand the images and prototypes that women,
who suffer from hypertension, have regarding their situation. It investigates how these women perceive
themselves in the family and social interaction. Twenty-one women, who were participants of a
control program of hypertension, in the suburbs of Fortaleza-Ceará, were the subjects of this study.
Results show that, according to the participants in the study, suffering from hypertension means 
experiencing difficulties and having limitations in social and family life. These women picture themselves as "different", since they live under the threat of death and disability, which causes psychic suffering. The constraints imposed by the disease keep these women aside from the regular social life.

KEYWORDS: women, arterial hypertension and social representations

RESUMEN: El estudio trata de las Representaciones Sociales de la hipertensión arterial y de sus causas, asi como intenta comprender las imágenes y prototipos de la mujer que padece hipertensión tiene sobre su situación; de que forma se ven en la familia e interactuando con los demás. En total fueron veintiuna mujeres que participaron de un programa de control de hipertensión que se desarrolló en los alrededores de Fortaleza - Ceará. Los resultados muestran que vivir con hipertensión es para esas mujeres una experiencia muy dificil y que poseen muchas limitaciones a nivel social y familiar. La imagen que ellas tienen de si mismas es de personas "diferentes", que viven bajo constante amenaza de muerte o de invalidez, lo cual las conlleva a un sufrimiento psiquico. Las varias restricciones impuestas por la enfermedad las deja - prácticamente- al margen de un convivio social normal.

PALABRAS CLAVE: mujeres, hipertensión arterial, Representaciones Sociales

\section{REFERÊNCIAS BIBLIOGRÁFICAS}

ALVES, M.G.M. A voz do hipertenso: representaçōes sociais da hipertensāo arterial- estudo de caso em Jurujuba, Niterói/RJ. 1998. 171f. Dissertaçăo ( Mestrado em Ciências) - Escola Nacional de Saúde Pública/ Fiocruz, Rio de Janeiro.

ALVES, P.C.; MINAYO, M.C.S. (Org.). Saúde e doença: um olhar antropológico. Rio de Janeiro: Fiocruz, 1994. 174p.

AMODEU, C. Hipertensäo arterial: como diagnosticar e tratar. Rev. Bras. Med., Săo Paulo, v.52, p.193200, dez. 1995.

BARDIN, L.A. Análise de conteúdo. Rio de Janeiro: Persona, 1977.

CERESER, H.L. A vivência familiar da mulher com hipertensäo arterial. 1996. 155f. Dissertação (Mestrado em Assistência de Enfermagem) - Universidade Federal de Santa Catarina, Florianópolis.

CONSENSO BRASILEIRO DE HIPERTENSĀO ARTERIAL, 3., 1998, Säo Paulo. Disponivel em: < http:/ /www.sbn.org.byconsui1.htm>. Acesso em:01 maio 1999.

DUARTE, L.F.; LEAL, O.F. (Org.). Doença, sofrimento, pertubação: perspectivas etnográficas. Rio de Janeiro: Fiocruz, 1998. 210p.

FIGUEIREDO, J.B. A. O Tao ecocêntrico: em busca de uma práxis ecológica. 1999. 154f. Dissertação (Mestrado em Saúde Pública) - Universidade Estadual do Ceará, Fortaleza.

MARTINS, I. S. et al. Doenças cardiovasculares arteroscleróticos dislipidemias, hipertensão, obesidade e diabetes melito em populaçăo da área metropolitana de regiāo Sudeste do Brasil: metodologia da pesquisa, 1. Rev. Saúde Pública, Säo Paulo, v.27, n.4, p.250-61, 1993.

MINAYO, M.C.S. O desafio do conhecimento: pesquisa qualitativa em saúde. 4. ed. São Paulo: Hucitec, 1996.

MOSCOVICI, S.A. A representação social da Psicanálise. Rio de Janeiro: Zahar,1978. 
PICCINI, R.X.; VICTORA, C.G. Hipertensão arterial sistêmica em área urbana no sul do Brasil: prevalência e fatores de risco. Rev. Saúde Pública, São Paulo, v.28, n.4, p.261-267,1994.

PITTA, A. Hospital: dor e morte como oficio. 4. ed. Săo Paulo: Hucitec, 1999. 198p.

RODRIGUES, M.S.P. Enfermagem: representação social das/os enfermeiras/os. Pelotas: UFPel, 1999.

SILVA, Y. F.; FRANCO, M.C. (Org.). Saúde e doença: uma abordagem cultural da enfermagem. Florianópolis: Papa-Livro, 1996. 120p.

SILVEIRA, M. L. O nervo cala, o nervo fala: a linguagem da doença. Rio de Janeiro: Fiocruz, 2000. $123 p$.

SPINK, M.J. Desvendando as teorias implicitas: uma metodologia de análise das representaçōes sociais. In: GUARESCHI, Pedrinho, A. ; JOVCHELOVICH, S. Textos em representação social. Petropólis: Vozes, 1995.

VACHOD, L.; SANTOS, R.S. Montando o quebra-cabeça das representações sociais: em estudo com gestantes de risco. Rev. Enferm. UERJ, Rio de Janeiro, Ediçāo Extra, p.23-37, 1996. 